\title{
Deformation prediction and anti floating analysis of a raft foundation
}

\author{
Binbin $\mathrm{Xu}^{1,2,3,4^{*}}$ \\ ${ }^{1}$ Tianjin Port Engineering Institute Co. Ltd. of CCCC First Harbor Engineering Co. Ltd., Tianjin, 300222, China \\ ${ }^{2}$ CCCC First Harbor Engineering Co. Ltd., Tianjin, 300461, China
}

${ }^{3}$ Key Lab. of Geotechnical Engineering of Tianjin, Tianjin, 300222, China

${ }^{4}$ Key Lab. of Geotechnical Engineering, Ministry of Communication, Tianjin, 300222, China

\begin{abstract}
This paper mainly studies the deformation and stress of the concrete plat under the uniform load considering the thickness of the compression layer of layered ground. Firstly, the load characteristics and the ground strategy are discussed in detail to clarify the boundary condition. Then the deformation of the ground in each layer is calculated by GEO-Cal program and the final settlement and uneven deformation is also predicted using consolidation theory. Ground stress and settlement is also calculated by FEM to verify the previous calculation.
\end{abstract}

\section{Project overview}

According to the general layout plan and borehole layout plan, the bottom plate of the reservoir is a large area concrete structure. Under the water load and model load, the foundation will produce obvious settlement. In addition, according to the geological survey report, the foundation compression layer within the scope of the reservoir is large and uneven in thickness, which is easy to produce uneven settlement ${ }^{[1-4]}$. In order to reduce the influence of uneven settlement on the concrete floor, the designer proposes to use pile foundation ${ }^{[5-6]}$.

In this paper, considering the influence of the different thickness of the compression layer of layered foundation, the settlement deformation of the reservoir foundation under the action of service load is studied, and the causes and changes of the uneven settlement are mainly analyzed. The research results can provide the basis for the later foundation selection.

\section{Load, soil layer distribution and soil property analysis}

\subsection{Load analysis}

The section and elevation of the reservoir are shown in Figure 1. It can be seen from Figure 4 that according to the converted Xingang elevation, the average elevation of the borehole within the scope of the reservoir is $+3.9 \mathrm{~m}$, while the designed outdoor floor elevation is $+4.9 \mathrm{~m}$, which indicates that the reservoir needs to be filled with $1 \mathrm{~m}$ high fill after the excavation. If the elevation of concrete floor is taken as the analysis object, the load acting on the surface before and after construction is shown in Figure 2, and the specific explanation is as follows:

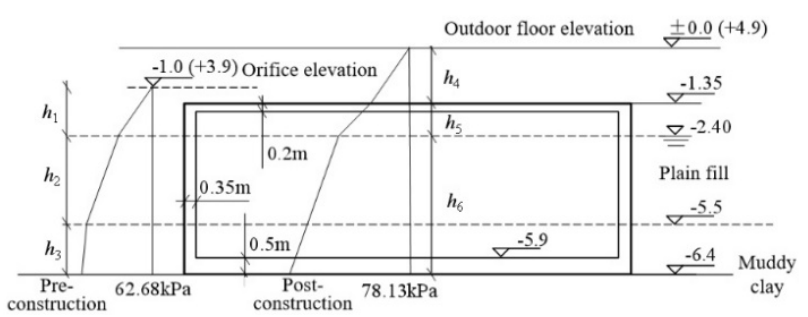

Figure 1. Elevation, size and load diagram of reservoir

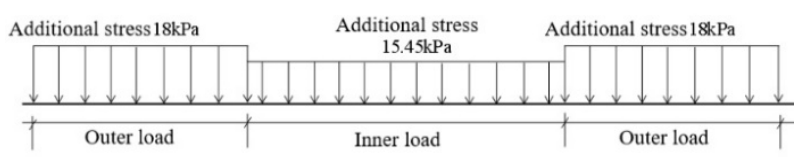

Figure 2. Schematic diagram of foundation action load on the bottom of reservoir

a) Pre-construction load within the scope of reservoir The pre construction load is the self weight stress of the soil at this depth. It should be noted that the relative elevation of the ground surface before construction is $1.0 \mathrm{~m}$, then the self weight stress is:

$$
\begin{gathered}
\gamma_{1} h_{1}+\left(\gamma_{1}-\gamma_{\mathrm{w}}\right) h_{2}+\left(\gamma_{2}-\gamma_{\mathrm{w}}\right) h_{3} \\
=19.2 * 1.4+9.4 * 3.1+7.4 * 0.9=62.68 \mathrm{kPa}
\end{gathered}
$$

b) Post-construction load within the scope of reservoir

\footnotetext{
*Corresponding author: 109930595@qq.com
} 
The post construction load includes the concrete weight acting on the bottom, which can be divided into the above water part and the underwater part (the groundwater level is taken as the relative elevation of $2.4 \mathrm{~m}$ ); the water weight when the reservoir is full of water and the soil weight on the reservoir. After calculation, the load of concrete acting on the foundation is $17.5 \mathrm{kpa}$, the water weight is $42.63 \mathrm{kpa}$, the overlying soil weight is $18 \mathrm{kpa}$, and the total load after construction is $78.13 \mathrm{kpa}$. Therefore, the additional stress acting on the foundation of the reservoir at the relative elevation of $-6.4 \mathrm{~m}$ is $15.45 \mathrm{kpa}$, which can also be regarded as a large area uniform load.

c) Additional stress on both sides of reservoir

When the additional stress of the foundation on both sides of the reservoir is $1 \mathrm{~m}$ at the relative elevation of $6.4 \mathrm{~m}$, the additional load is $18 \mathrm{kpa}$.

\subsection{Soil distribution}

According to the drilling data, it can be divided into ten layers from top to bottom, mainly including plain fill 1 , muddy clay $2 \mathrm{a}$, silty clay $2 \mathrm{~B}$, muddy clay $2 \mathrm{c}$, silty clay $2 \mathrm{~d}$, silty clay 3 , silty clay $4 \mathrm{a}$, silty clay $4 \mathrm{~b}$, silty clay $4 \mathrm{c}$ and clay $5 \mathrm{a}$. The thickness of soft soil mucky clay $2 \mathrm{c}$ and silty clay $2 \mathrm{~d}$ in the hydraulic hall is the most uneven, while the thickness of soft soil mucky clay $2 \mathrm{a}$, silty clay $2 \mathrm{~b}$ and mucky clay $2 \mathrm{c}$ in the reservoir is the most uneven.

\subsection{Soil parameters}

The indoor test results of 875 undisturbed soil samples and 88 disturbed soil samples collected in this survey are stratified according to the engineering geology (from top to bottom are plain fill, muddy clay, silty clay, silt, silt, silty clay, silt, etc.), and the statistical results are listed in Table 1 .

Table1. Model size

\begin{tabular}{|c|c|c|c|c|c|}
\hline Layer & $\gamma\left(\mathrm{kN} / \mathrm{m}^{3}\right)$ & $E(\mathrm{Mpa})$ & $k$ & $\mathrm{c}$ & $\varphi\left(^{\circ}\right)$ \\
\hline plain fill & 19.2 & 4.3 & $7.9 \mathrm{e}-8$ & 11.02 & 6.02 \\
\hline $\begin{array}{c}\text { muddy } \\
\text { clay }\end{array}$ & 17.2 & 2.6 & $4.6 \mathrm{e}-8$ & 6.74 & 1.86 \\
\hline silty clay & 19.6 & 6.0 & $3.0 \mathrm{e}-8$ & 12.08 & 7.89 \\
\hline silt & 17.9 & 2.8 & $2.9 \mathrm{e}-8$ & 10.58 & 2.30 \\
\hline silty clay & 20.2 & 9.1 & $2.8 \mathrm{e}-8$ & 2.43 & 27.25 \\
\hline silty clay & 19.8 & 5.1 & $3.5 \mathrm{e}-8$ & 13.49 & 5.75 \\
\hline silt & 20.1 & 5.8 & $7.0 \mathrm{e}-8$ & 17.16 & 11.83 \\
\hline silty clay & 19.8 & 10.6 & $3.0 \mathrm{e}-8$ & 1.78 & 29.43 \\
\hline clay & 19.2 & 4.8 & $6.8 \mathrm{e}-8$ & 19.24 & 8.16 \\
\hline
\end{tabular}

\section{Settlement calculation}

\subsection{Calculation conditions}

According to the general planning plan and the layout plan of boreholes, the B-B geological section in Figure 1 is determined as the calculation section. The boreholes included in the scope of pool foundation are $\mathrm{zk} 46, \mathrm{zk} 47$, zk48 and zk49.
The length of the reservoir is about $70 \mathrm{~m}$ and the width is about $15.9 \mathrm{~m}$. The bottom surface of the bottom plate of the reservoir is taken as the ground surface. The load acting on both sides of the reservoir is detailed in the chapter of load analysis. Figure 3 shows the stratigraphic profile along the length of the pool. In order to calculate the settlement value of the surface and stratum in the depth direction, the coordinate origin $(0,0)$ is set at the midpoint of the surface pool length, which is the $x$ axis along the surface and the $z$ axis in the depth direction.

In addition, in order to consider the consolidation degree of foundation at different time, the consolidation degrees of 200d, 300d, 10y, 20y, 30y, 40y and 50y are calculated respectively. Considering the influence of layered soil layer, the consolidation coefficient of foundation is calculated as $C \mathrm{v}=\left(\sum H \mathrm{i}\right) /\left(\sum H \mathrm{i} / \mathrm{Cvi}\right)$.

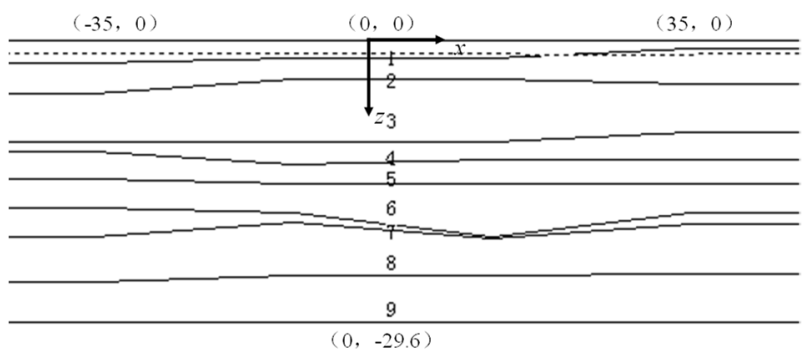

Figure 3. Calculation of soil layer and "block" division

\subsection{Calculation results and analysis}

Table 2 lists the corresponding soil layer compression at different positions of the reservoir bottom foundation, the soil layer with the largest compression, the total surface settlement and the uneven surface settlement, in which the empirical coefficient of foundation settlement is 1.3. Figure 4 shows the compression of each layer of soil at different coordinates, and the uneven compression of silt layer and muddy clay layer is the most obvious. Figures 5 and 6 show the variation of the total settlement and the average degree of consolidation of the foundation at the bottom of the reservoir at different coordinates at different times. Due to the drainage conditions and soil permeability, the foundation consolidation is slow, and it takes a long time to complete the whole consolidation process. Table 3 shows the magnitude of the differential settlement at the bottom of the reservoir at different consolidation stages.

Table2. Compression of each layer and total surface settlement at different coordinates under the reservoir

\begin{tabular}{|c|c|c|c|c|c|c|c|c|}
\hline & -35 & -25 & -15 & -5 & 5 & 15 & 25 & 35 \\
\hline 1 & $\mathbf{0 . 0 7 9}$ & 0.076 & 0.070 & 0.067 & 0.067 & 0.066 & 0.060 & 0.051 \\
\hline 2 & 0.026 & 0.024 & 0.022 & 0.020 & 0.020 & 0.021 & 0.024 & 0.029 \\
\hline 3 & 0.071 & $\mathbf{0 . 0 8 1}$ & $\mathbf{0 . 0 9 1}$ & $\mathbf{0 . 0 9 8}$ & $\mathbf{0 . 0 9 8}$ & $\mathbf{0 . 0 9 8}$ & $\mathbf{0 . 0 9 1}$ & $\mathbf{0 . 0 8 2}$ \\
\hline 4 & 0.011 & 0.016 & 0.021 & 0.023 & 0.022 & 0.020 & 0.022 & 0.026 \\
\hline 5 & 0.016 & 0.014 & 0.012 & 0.011 & 0.012 & 0.013 & 0.013 & 0.013 \\
\hline 6 & 0.019 & 0.019 & 0.020 & 0.022 & 0.027 & 0.032 & 0.030 & 0.024 \\
\hline 7 & 0.014 & 0.011 & 0.007 & 0.004 & 0.003 & 0.001 & 0.002 & 0.004 \\
\hline 8 & 0.021 & 0.023 & 0.024 & 0.025 & 0.021 & 0.018 & 0.019 & 0.021 \\
\hline 9 & 0.022 & 0.023 & 0.025 & 0.025 & 0.025 & 0.025 & 0.025 & 0.026 \\
\hline Max. & 1 & 3 & 3 & 3 & 3 & 3 & 3 & 3 \\
\hline
\end{tabular}




\begin{tabular}{|l|l|l|l|l|l|l|l|l|}
\hline Total & 0.278 & 0.286 & 0.291 & 0.296 & 0.295 & 0.294 & 0.287 & 0.275 \\
\hline & \multicolumn{1}{|c|}{ Maximum settlement $0.296 \mathrm{~m}$ is located at $-5 \mathrm{~m}$, and minimum $0.275 \mathrm{~m}$ is } \\
located at 35m. Uneven settlement is $2.1 \mathrm{~cm}$.
\end{tabular}

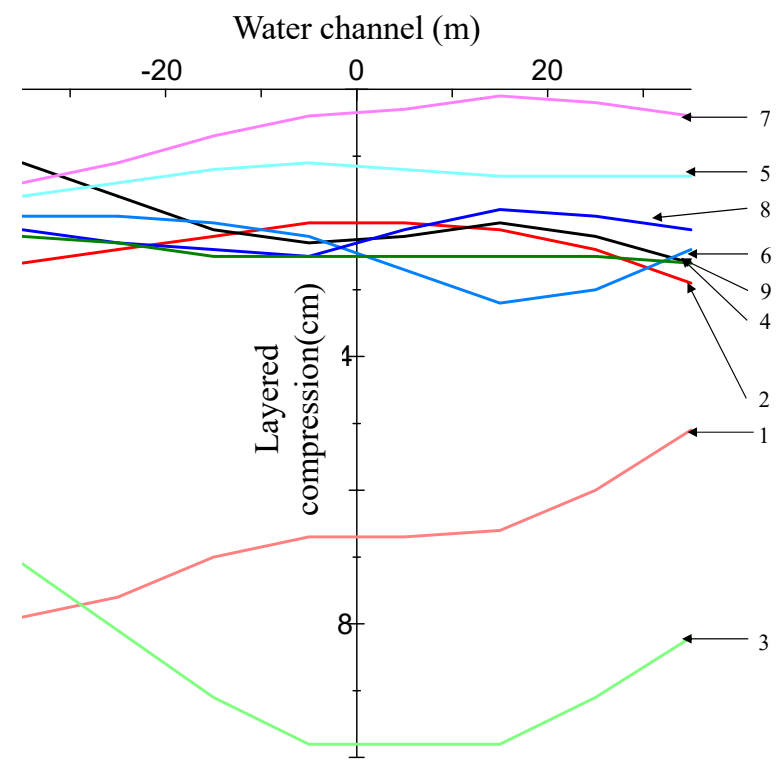

Figure 4. Calculation of soil layer and "block" division

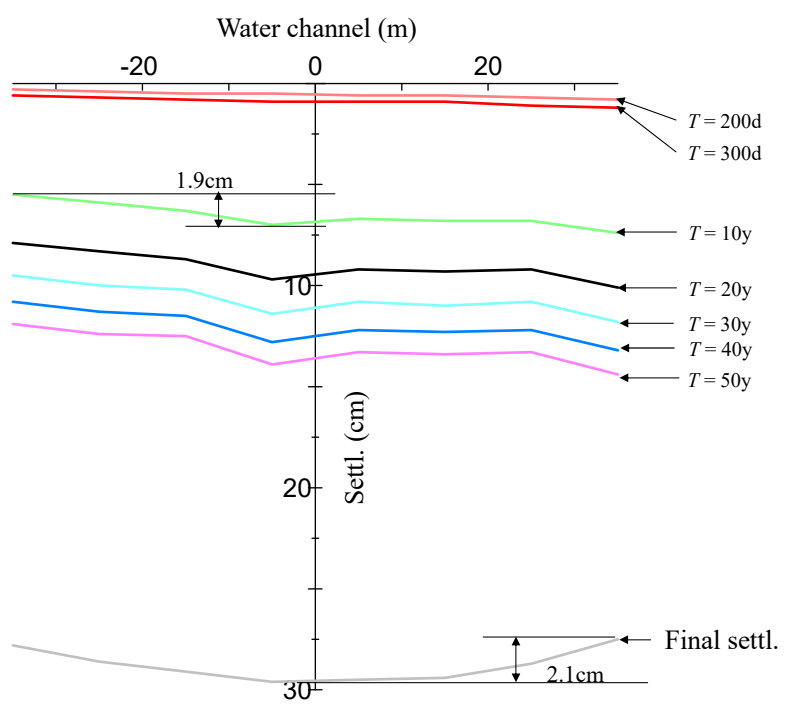

Figure 5. Total settlement at different coordinates at different time of reservoir bottom

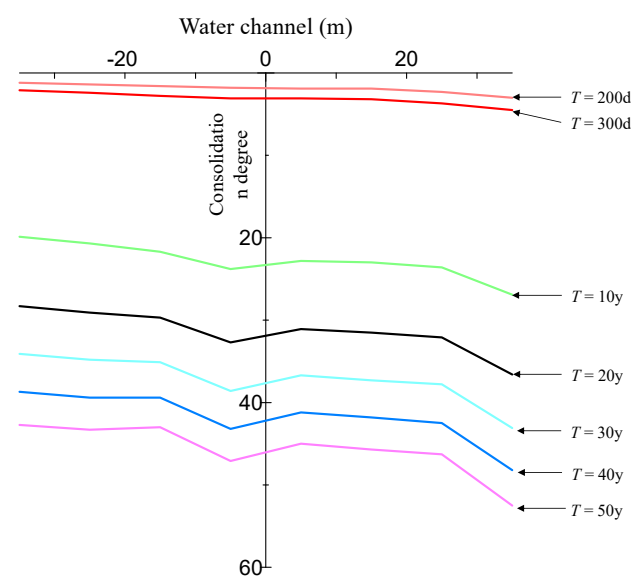

Figure 6. Average consolidation degree of foundation at different coordinates at different times at the bottom of reservoir

\subsection{Finite element results}

In order to ensure the accuracy of the calculation results, PLAXIS 3D finite element software is used to calculate the foundation settlement of the reservoir. In the calculation, the soil parameters of ZK46 ZK49 drilling wells are selected. The physical and mechanical indexes are shown in Table 1 and the calculation conditions are the same as those in 3.2. The numerical model of PLAXIS after meshing is shown in Figure 7.

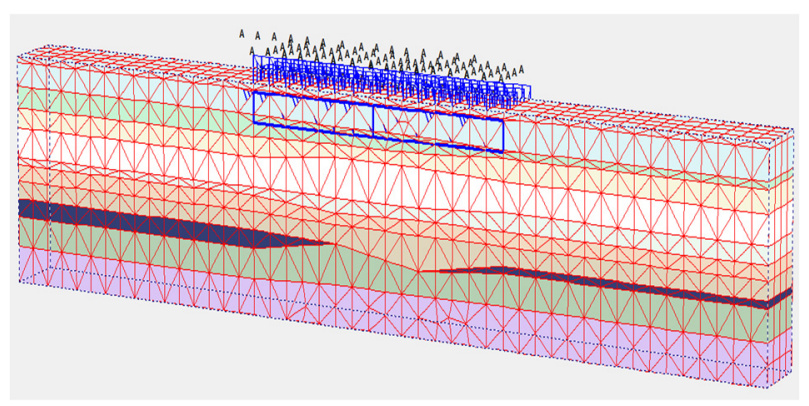

Figure 7. Numerical model after meshing

Because of the discontinuity of the soil layer in this case, in order to ensure the accuracy of the calculation, the location of the discontinuous soil layer is locally optimized in grid time sharing. The distribution of groundwater in the calculation is the same as that in 3.2, and the hydrostatic pressure calculated by PLAXIS 3D finite element is shown in Figure 8. It can be seen from figure 30 that the maximum hydrostatic pressure generated by the foundation is $356 \mathrm{kPa}$.

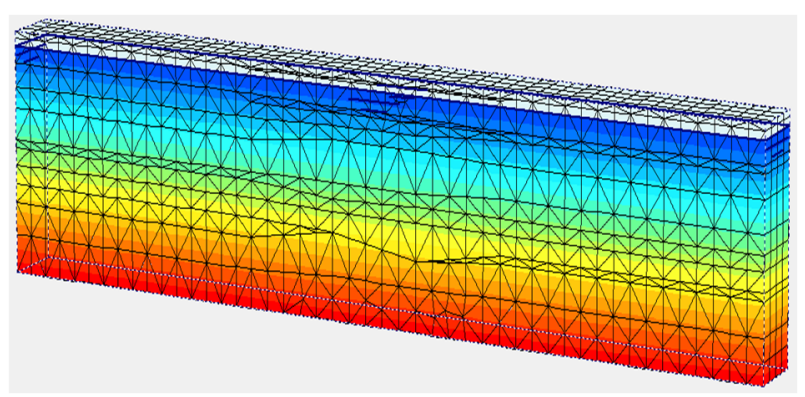

Figure 8. Hydrostatic pressure $(\mathrm{kPa})$

It can be seen from figure 9 that the settlement at different locations of the reservoir foundation is different. The maximum settlement occurs at $x=-5 \mathrm{~m}$, and the maximum settlement is $23.2 \mathrm{~cm}$. The effective stress of foundation soil is shown in Figure 10.

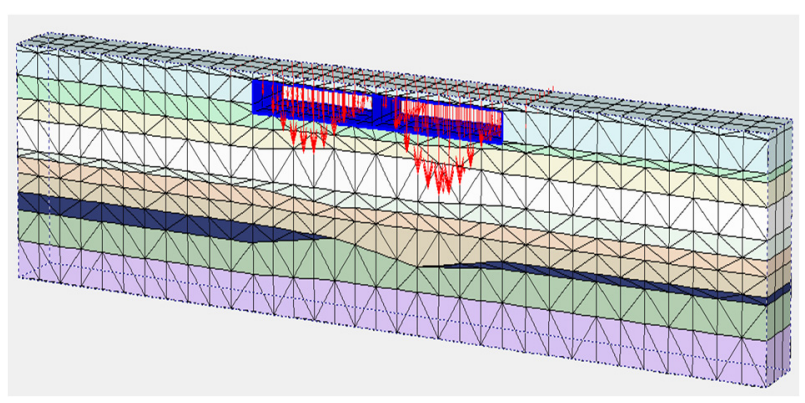

Figure 9. Vector diagram of foundation settlement (m) 


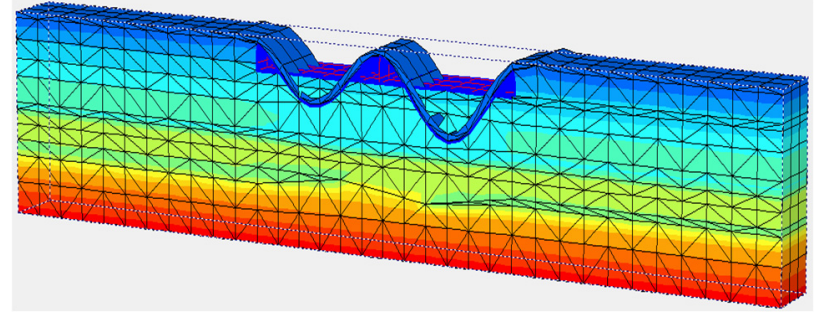

Figure 10. Effective stress of foundation $(\mathrm{kPa})$

It can be seen from Figure 10 that the maximum effective stress produced by the foundation is compressive stress, which is $500 \mathrm{kPa}$. The calculated stress of the reservoir is shown in Figure 9.

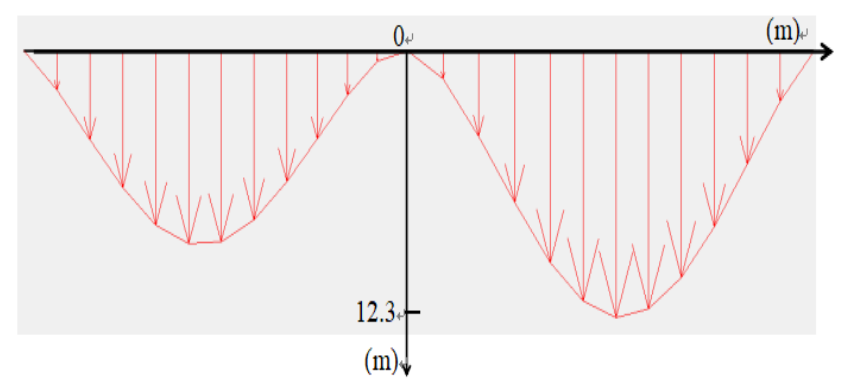

(a) Vertical displacement of reservoir (m)

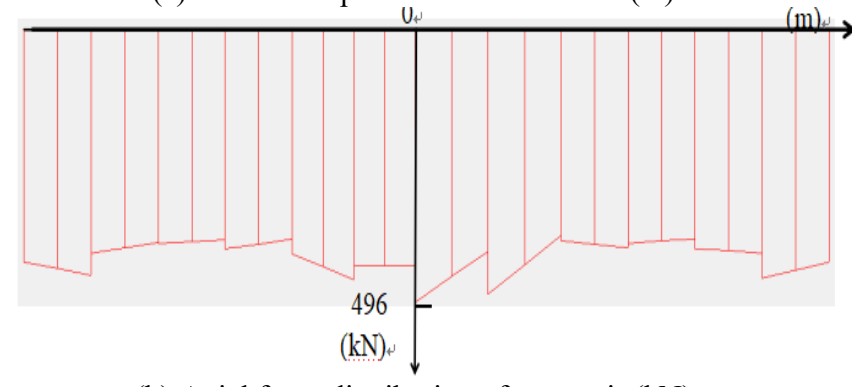

(b) Axial force distribution of reservoir $(\mathrm{kN})$

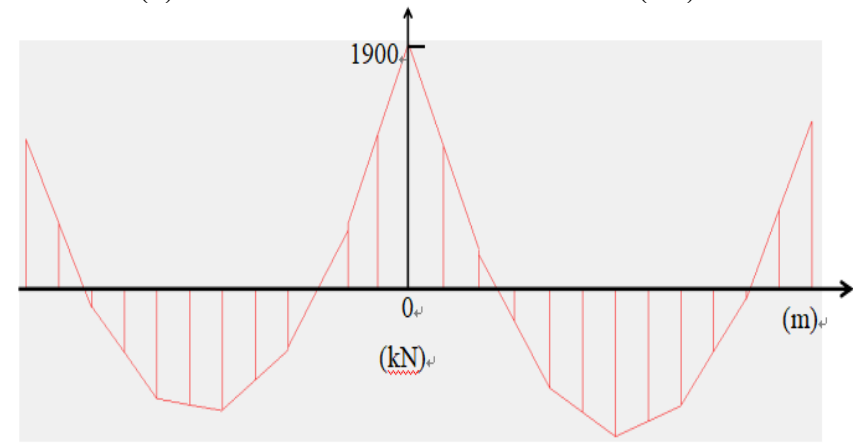

(c) Moment distribution diagram of reservoir $(\mathrm{kNm})$

Figure 11. Stress of reservoir

It can be seen from Figure 11 that the maximum vertical displacement of the reservoir is $12.3 \mathrm{~cm}$, the axial force is compressive stress, the maximum value is $496 \mathrm{kN}$, and the maximum bending moment is $1900 \mathrm{kNm}$. The maximum compressive stress of the reservoir is $3.6 \mathrm{MPa}$ calculated from the most unfavorable load combination of maximum pressure and maximum bending moment.

\section{Conclusions}

The settlement deformation and anti floating of the foundation under the concrete floor of the reservoir are analyzed in detail. The main conclusions are as follows:

(1) The results show that the uneven compression of silt layer and muddy clay layer is the most obvious, and the final uneven settlement is only $2.1 \mathrm{~cm}$.

(2) Because the empirical coefficient of 1.3 is selected in the calculation of settlement by the port engineering foundation calculation system, the calculation results of the finite element method are expanded by 1.3 times. Compared with the results of the port engineering foundation calculation system, when the service load is $2 t$, the maximum difference between the two methods is less than $0.7 \%$, and the maximum settlement of the reservoir foundation calculated by the two methods is less than $0.7 \%$ The maximum difference is less than $2 \%$.

(3) In the finite element calculation, the surface uneven settlement is $4.7 \mathrm{~cm}$ without raft foundation, 2.3 $\mathrm{cm}$ with raft foundation, the maximum tensile stress is $48.7 \mathrm{kN}$, the maximum bending moment is $790.3 \mathrm{kNm}$, and the maximum compressive stress is $0.26 \mathrm{MPa}$.

\section{References}

1. F. Han, H.M. Han, L.Q. Zou, ShangDong Land and Resources 35, 11 (2019)

2. H.W. Zhang, Transportation Standardization 42,8 (2014)

3. B.X. Li, Transpo World 1, 3 (2016)

4. Y.L. Qiao, G.H. Yang, Y.C. Zhang, Guangdong Water Resources and Hydropower 7 (2013)

5. Q.J. Jiang, Architecture \& Culture, 10 (2013)

6. W.X. Cui, Journal of railway engineering society, 4 (2009)

7. G.Y. Wang, J. Yu, S.G. Wu, J.Q. Wu, Geology and exploration 45, (5) (2009)

8. R.L. Hua, L.C. Wang, Z.Q. Yue, Engineering Geology 76, 1 (2004) 